\title{
LANGUAGE FUNCTIONS USED BY THE CARETAKERS OF AUTISTIC CHILDREN IN "MIRACLE RUN"
}

\author{
Agwin Degaf \\ Universitas Gadjah Mada Yogyakarta
}

\begin{abstract}
This study investigates language functions used by the caretakers of autistic children in "Miracle Run". The objectives of the study are to find out the kinds and the effectiveness of language functions used by caretakers in the film. This study uses descriptive qualitative approach. It is categorized as discourse analysis because this study analyzes phenomena of talk in interaction. The data are collected from the utterances used by the caretakers; they are mother, doctor, teacher, and therapist when talk to the autistic children and those are analyzed by using M.A.K Halliday theory on language functions.
\end{abstract}

Key words: Language Functions, Caretaker Speech, Autistic Children.

\section{INTRODUCTION}

Adults definitely should make such adjustments in their speech very often when talking to children with special educational handicap, specifically with autistic children. Children with autism, like other children, have a unique personality and combination of characteristics (Ruswan, 2005: 2). They have difficulties communicating, maintaining a conversation or keeping a conversation going. In general, an autistic child has problems in understanding what he is talking about. At the same time, an autistic child also has problems to understand what adult say.

Autistic children needs help from other people such as; parents in home, therapist in autistic therapy, and teacher in school. It is because they spend a lot of time helping autistic children to learn how to do something or how to understand a word by making some adjustment in their utterances (Anderson, 1989). In talking autistic children; parents, therapist, and teacher use special ways which are different when they are talking to normal children like use a simple sentence, clear voice, and sometimes using low and soft tones (Caldwell, 2010). According to Yule (1985: 177), the characteristically simplified speech style adopted by someone such as mom, dad, granny and grandpa, who spends a lot of time interacting with a young child is called caretaker speech. As the definition suggest, one of the characteristics of the caretaker speech must be simple, which means simple sentence structures. People that talk with autistic children have to modify their speech when talking with autistic children. They must be able to gain the trust of the child and create an 
environment in which the child enjoys having them around (Ruswan, 2005: 2). In general, they will enrich autistic children's knowledge in improving their sentences and developing their awareness of what the purpose of language function is.

Based on Halliday's theory (1992: 11), there are seven classifications of functions of language. They are instrumental functions, regulatory function, representational function, interactional function, personal function, heuristic function, and imaginative function. Each of those functions has its own characteristics and purposes; also, all of them are usually used by adults to know the child's image of language, so they can modify their language when communicating with children.

The study about language function is studied by Discourse Analysts. "Discourse analysts study language in use: written text of all kinds and spoken data, from conversation to highly institutionalized forms of talk" (McCarthy, 1991: 15). The examples of written discourse are articles, novel, short story, and so on. Meanwhile, speech, lecture, dialogue, debate, conversation, and so on are considered as spoken discourse. More particularly the study about language function in lecture is studied by conversation analyst as an approach to analysis of spoken discourse.

As cited by Kessler from Olsen, language functions refer to the way we can use language to achieve communication process, 1.e. to get listeners to understand what we are saying (Kessler, 1992: 92). We use language, specifically sentences, as a tool to help us to say what we have in mind to others. Barnes (1973) makes a distinction that sentence performs two functions at once. It conveys the overt message and at the same time sets up or confirms the social identity and relationship of the people who are speaking or writing to one another (Holmes, 1978: 139).

In this case, functions of language are chosen to be analyzed because language itself serves a range of functions, such as: for the media of personal relationship, for creating the imaginary systems and so on. An utterance may have one or more functions depending on the context of the situation, while variation in sentence forms may carry the same function (Kessler, 1992: 92). As said Dale, most of people who have had experience speaking with little children have strong feelings that their speech with little is quite different from their other speech (Dale, 1972: 37). Considering those facts, the researcher found a film which demonstrates conversation process between adult as a caretaker and autistic twin children, under the title "Miracle Run". 
This study focused on the analysis of language function used in the dialogue between the caretakers with autistic twin children in "Miracle Run". The data source of this study was "Miracle Run". From the data source, the researcher analyzed and investigated the utterances in talk with autistic children based on time sequence appearance which was dealing with language function as the data. The choice of utterances by the caretakers in talking to autistic children as a primary data because it could perform different types of language functions. The objectives of this study are to describe the types and the effective types of language functions used by the caretakers in talking to autistic children in 'Miracle Run'. To understand the phenomena, the researcher applies the Halliday's Theory that may be the most appropriate to investigate language functions used by the caretakers of autistic children in "Miracle Run".

\section{THEORY OF LANGUAGE FUNCTIONS}

Based on Halliday's theory (1992: 11), there are seven classifications of functions of language. They are: instrumental functions, Regulatory function, Representational function, Interactional function, Personal function, Heuristic function, and the last are imaginative function. Each of those functions has its own characteristics and purposes; also, all of them are usually used by adults to know the child's image of language, so they can modify their language when communicating with children.

The seven classifications of functions of language proposed by Halliday can be seen through the explanation as follows:

\section{Instrumental Function}

The instrumental function serves to manipulate and control the environment, to cause certain events to happen as well as to satisfy material needs. It is a tool of getting things done which is known as the "I want function", including "I do no want" as well (Halliday, 1992: 11). Here, the child has developed a meaning potential in which he or she can request goods or services, the latter in the form either of physical assistance or of having something made available to him or her. In addition, his or her demand may be in response to a question "Do you want...?" In which case the answer may be positive or negative; or it may be initiated him/herself, in which case it always positive. For example: "I want banana" or "I do no want bread".

\section{Regulatory Function}

The regulatory function is used to manage the behavior of others, to manipulate the person in the environment, which is known as "do as I tell you" function. It is a language of 
rules and instruction (Halliday, 1992: 12). For example: the mother who finds that her small child has carried out of the supermarket's things unnoticed by herself or by the cashier, may exploit the power of language in various ways, "you will make me very unhappy if you do that" (control through emotional blackmail); "that's not allowed" (control through categorization of behavior as governed by rule); "that was very naughty" (control through categorization of behavior in terms of opposition approved/disapproved); you mustn't take things that don't belong to you (control through conditional prohibition based on a categorization of objects in term of a particular social institution, that of ownership); if you do that again I'll smack you (control through threat of reprisal linked to repetition of behavior).

\section{Representational Function}

The representational function is the use of language to make statements and propositions, convey facts and knowledge, explain or report-that is to present reality as one sees it. It conveys a message which has specific reference to the process, persons, objects, abstractions, qualities, and relations of real world around the speaker (Halliday, 1992: 17). It is an "I have got something to tell you" function and this is the only function that many adults have because they already have knowledge to interpret something which they have seen it, while the little children do not have many experiences to see and understand all things in this life yet. For example: “yesterday, I saw a small-beautiful butterfly. Its colors were red, blue, yellow, and green".

\section{Interactional Function}

The interactional function serves to ensure social maintenance, establish social contact and keep channels of communication open; the "me and you" function of language including "me and my mummy" (Halliday, 1992: 13). Here the child is either interacting with someone who is present (greeting) or seeking to interact with someone who is absent (calling). All utterances in this function end on a high rising tone, unless it replaced by a gesture. In this function, there are two types of utterances, those requiring a response and those not. Moreover, this function also involves a specific person, but he is not being required to do anything, merely to be there and in touch. Successful interactional communication requires knowledge of slang, jargon, folklore, cultural mores, politeness and formality expectations, and other keys to social exchange. For examples: "good morning, class!" 


\section{Personal Function}

The personal function allows a speaker to express his own individuality (feelings, personality and emotion) and is known as "here I come" function (Halliday, 1992: 17). It can be called as language used for the direct expression of feeling attitudes, for example: "I love my friend" or "I am very sad". A person's individuality is usually characterized by his/her use of the personal function of communication.

\section{Heuristic Function}

The heuristic function refers to language as a means of investigating reality, way of learning about things. It derived from the child's knowledge of how language has enabled him to explore his environment. Furthermore, it is often conveyed in the form of questions that will lead to answer, is known as "tell me why" function (Halliday, 1992: 17). Children typically make good use of this function in their incessant "why" questions about the world around them. When he is questioning, he is seeking not merely facts but explanations of facts, the generalizations about reality that language makes it possible to explore, for instances, "why we should not lie?" or "why we do not allow to eat candy too much?"

\section{Imaginative Function}

The imaginative function serves to create imaginary systems or ideas. Telling fairy tales, joking, writing a novel, poetry, tongue twisters, puns are all applications of the imaginative function (Halliday, 1992: 15). Language in imaginative function can be when someone adults rendering of children's rhymes and songs, which are often very dramatic, with an intonation and rhythm appropriate to the content. It is also known as the "let's pretend" function, for example, "the king of jungle has loud and frighten voice".

The researcher chooses the above seven classifications of functions of language because these functions are the child's image of language. "Children usually use these function to internalize their experience" (Halliday, 1992: 11). These functions will guide the adults about what is relevant to them in speaking to children, since their own view of language must at the very least encompass all that the children know language to be.

\section{CARETAKER SPEECH}

Since this study mainly focused on the way an adult speak to a child, and then the researcher feels that it is necessary to put some theories of caretaker speech. There are so many experts that define about caretaker speech; for example, Yule (1985: 139). He defined 
caretaker speech as the characteristically simplified speech style adopted by someone, who spends a lot of time interacting with a young child. As the definition suggests, one of the characteristics of the caretaker speech must be simple, which means simple sentences structures. Yule also adds that caretaker speech is also characterized by frequent questions, exaggerated intonation and a lot of repetition.

Another example is Littlewood (1984: 15) that collected a number of observational studies of language addressed to small children by mothers, other adults or older children and made a number of characteristics of the typical speech into; it is generally spoken more slowly and distinctly, it contains shorter utterances, it is more grammatical with fewer broken sentences or false starts, it contains fewer complex sentences (e.g. with two clauses), there is less variety of tenses, the range of vocabulary is more limited, there is more repetition, the speech is more closely related to the 'here and now'.

Through these two examples, we can see clearly that Littlewood goes into more detailed characteristics of the caretaker speech than Yule's theory, but there is still a possibility that both can complete each other. As the researcher thinks that it will better to find another theory to make a more complete source to identify and classify the data, he found Lightbrown and Spada's (1993). They define caretaker speech as the speech directed to children. In English, caretaker speech involves: slower rate of speech, higher pitch, more varied intonation, shorter, simple sentence patterns, frequent repetition, Paraphrase, topics of conversations are of ten limited to the child's immediate environment, the 'here and now'. Likewise, Dale (1972) proposes that mother-to-child speech is characterizing by smaller vocabulary, shorter sentences, less complex sentences, more use of intonation, and clearer articulation.

For further information, Clark and Clark (1977: 320) explain that several recent studies have shown that adults tend to use very short grammatical sentences when talking to young children. These observations contradict earlier claims that the language children hear contains numerous ungrammatical forms, hesitations, changes of construction, and mistakes. In relation with 'here and now' speech, Clark and Clark (1997: 322-324) write that in talking about the 'here and now' - usually whatever is directly under the child's eyes - adults are usually very selective about the words they use. They seem to be guided by the following assumptions: 
1. Some words are easier for children to pronounce than others

Most language contains 'baby talk' words that are considered appropriate in talking to very young children. For example, adult speakers of English often replace the word for animals by words for their sounds - meow, woof-woof — or by a diminutive form of the adult word-kitty, doggie. Adults appear to use baby talk words because seem to be easier for children to pronounce.

2. Some words are more useful for children than others

R. Brown (1985) argued that he words parents use in speaking to young children anticipate the nature of the child's world. This seems to be true not only of baby talk words but also of the other words used in speaking to young children. Adults select the words that seem to have the most immediate relevance to what their children might want to talk about. For instance, they supply words for different kind of fruit the child might eat, such as apple o orange, but not the word fruit. They likewise supply the names of animals, but not the word animal. In other domains, though they provide more general words-like tree-and do not use the more specific words for different kinds of tree-like oak, ash or birch. The criterion adults seem to use characterized by what Brown called 'level of utility' the judgment that one word is more likely to be useful than another in the child's own utterances.

3. Some words are hard to understand and best avoided

Adults are also selective in another way too: they omit some words and word endings and avoid other words. Snow found that adults used fewer word endings (e.g. plural $-s$ or possessive $-s$ ) and articles (the, $a$ ) when speaking to two-year-olds than to ten-year-olds, than to adults (Snow, 1972).

The three assumptions give deeper understanding to the researcher about "here and now" speech. Through all those theories which the researcher finds, he sees that mostly all the theories perform more or less the same thing about the characteristics of caretaker speech, such as simple short sentences, using a lot of repetition, vocabulary is limited. Therefore, from all those theories, the researcher can summarize the theories into the following characteristics: slower rate of speech, shorter utterances, and simpler sentence patterns, vocabulary is more limited, lots of repetition, frequent questions, the speech is 'here and now', clearer articulation, and paraphrase. 


\section{RESEARCH METHOD}

This study used descriptive qualitative approach, since it analyzed the data in the form of utterances descriptively based on language functions found in the film. It attempted to describe phenomena that happen in human life and it was hard to measure the data quantitatively since the data were in the form of words, utterances, or conversations. This study emphasized on the specific case-language functions using Halliday's theory to analyze the utterance of the caretakers who made some caretaker speech to autistic children in "Miracle Run".

For the data procedure, the researcher collected the data by watching the film based on the time sequence appearance and transcribing the utterances into written text. Firstly, the researcher watched the film in order to get deep understanding about how the caretakers talk to autistic children. Then, the researcher transcribed the dialogue into text. Lastly, after making a transcription, the researcher coded the dialogue that performing language functions from the beginning up to the end based on the time sequence appearance.

A transcript of "Miracle Run" film would assist the analysis of the utterances. Here, this study did not assume transcript as data because as stated in Hutchby and Wooffitt (1998: 73-74). It was important to stress that transcript were not thought of as "the data". The data consist of tape recordings may be audio or video naturally occurring interactions. The transcript was seen as a "representation" of the data; while the type itself was viewed as a "reproduction" of a determinate social event. It is also supported by Wooffitt (2006: 13) that the transcript is merely an aid in the analysis of the events recorded on tape.

Based on the research problem, the researcher got the data by transcribing the film dialogues into text and documenting. The researcher did reduction data in which the researcher took field note then paraphrases and selects the data relevant with the research problems. While doing reduction, the researcher coded the data by selecting important and appropriate utterances with the research problems based on the time sequence. After that, the data were analyzed through the following steps. First, in the section data presentation and analysis, the data were presented and analyzed based on the time sequence appearance. For each the time sequence appearance, the datum was analyzed to find the type of language functions and the effective language functions used in each datum based on theory of language functions proposed by Halliday (1992). The language functions are instrumental function, regulatory function, representational function, interactional function, personal function, heuristic function and the last is imaginative function. The effective language 
functions was a function that got response whether verbal or non verbal from the autistic children.

\begin{abstract}
ANALYSIS
The data analysis presentation is based on time sequence appearance. The codes on each datum represent the number of datum and caretaker speech data. Besides, the data analysis is explained directly after displaying the data. The description and identification of language functions are used by the caretakers of autistic children in "Miracle Run" are as follows:
\end{abstract}

\title{
Datum 1
}

\section{Context:}

In bedroom, Corrine Morgan-Thomas as mother visited their children to give a glass of milk to Steven and also information if they were going to somewhere together. Her children's names were Phillip and Steven. Both of them were autistic children. At that time, Philip was watching Superman on TV while Steven was drawing an American map on his drawing paper. Mother came to the room and gives a glass of milk to Steven.

\section{Utterances:}

\section{Mother: (1.1) Hold!}

(Mother held Steven's hand and helped him to hold a glass of milk even though he was still drawing).

\section{(1.2) Oh Steven that's beautiful}

(Mother saw the work of Steven).

(1.3) Almost time to go guys!

(Mother looked towards Philip then walked out of the room).

\section{Data Analysis:}

In datum 1, mother as the caretaker produces three kinds of utterances. On 1.1 and 1.3 , she uses regulatory function. It is because she gives a command to her autistic children in order to get an attention to follow her instructions. On 1.1, she gives a command to Steven to hold a glass of milk. She also uses physical prompt because Steven needs physically help to response correctly about her command. In this case, she puts a glass in Steven's hand. So that, Steven better understands what her mother orders even though Steven is still drawing. On 1.3, mother asks her two children to get ready because they will go somewhere soon but her children do not give any response. As result, only on 1.3, Steven gives a response by doing what his mother commanded. 
On 1.2, mother as the caretaker uses personal function. It is because she wants to express her own feeling about Steven's drawing enthusiastically because she knows that Steven can draw the U.S. map. That is why; she says that Steven's drawing is beautiful.

In conclusion, datum 1 consists of three utterances. They have two different language functions as well, such as regulatory function (1.1 and 1.3), and personal function (1.2). All two kinds of language functions above are not responded by the autistic children verbally. Yet, on 1.1, Steven responds nonverbally to what his mother says even though he also gets some help by physical prompt from his mother to perform the command. It shows that regulatory function here is effectively used by the caretaker.

\section{Datum 2}

\section{Context:}

In a car, Corrine-Morgan Thomas took both her autistic children to see a child specialist doctor named Patrick. During the way to a hospital, Corinne Morgan Thomas tried to explain to her autistic children that Doctor Patrick was a very nice person and they would surely love her. In this setting, Steven was shredding paper and Philip was just sitting quietly.

\section{Utterances:}

Mother: (2.1) This new doctor's very nice.

(Mother was driving the car, while looking at the mirror she said to her children)

(2.2) I think you guys will like her

\section{Data Analysis:}

(Mother still looked towards the mirror with a faint smile).

In datum 2, mother as the caretaker produces two kinds of utterances. On 2.1 and 2.2, mother uses personal function. It is because she says that the new doctor is very nice. It means that mother wants to express her own feeling about the new doctor which is better than other doctor before. Mother also makes a personal judgment that their autistic children will like the new doctor. In this setting, both of the autistic children do not care about what their mother has said. Steven is still shredding paper and Philip is just sitting quietly.

In conclusion, datum 2 consists of two utterances. They have the same language function, personal function. In this case, both of Steven and Philip do not give any comment about what her mother has said. It means that personal function is not effective for this kind of situation because the autistic children do not give any response and still do their own activity. 


\section{Datum 3}

\section{Context:}

In hospital, Corrine-Morgan Thomas and her children were in hospital to see Doctor Patrick. Then mother told the Doctor that they had seen half a dozen doctors and they all said the same thing. The other doctor said that both of Steven and Philip were healthy and usually twins developed their own language. Doctor Patrick then tries to make a little conversation with Steven and Philip.

\section{Utterances:}

Doctor Patrick: (3.1) Hi Guys, Can you tell me what your name is?

(Doctor Patrick was sitting in front of Steven and Philip then took a pen from his pocket to make notes on a book).

(3.2) and where do you live?

(Philip was looking up ceiling and he did not ignore what Doctor Patrick said to him).

(3.3) you live up there?

\section{Data Analysis:}

(Doctor was asking again to Philip because Philip was still looking up).

In datum 3, Doctor Patrick as the caretaker produces three kinds of utterances. On 3.1, 3.2 and 3.3, Doctor Patrick uses interactional function. It is because she wants to make an enjoyable situation. It makes Doctor Patrick easier to communicate with autistic twin children. Dr. Patrick also uses a high rising tone while speaking in order to get attention from Steven and Phillip. Although there is no response from the autistic children, she still greets them by changing her question. In this case, the doctor actually wants children to answer but her question does not work well because they do not give any response to her questions.

In conclusion, datum 3 consists of three utterances. They have the same language function, interactional function. In this case, the interactional function is not effective to make a verbal communication with the autistic twin children. It shows when Philip even look up when the doctor asks Philip.

\section{Datum 4}

\section{Context:}

Corinne-Morgan Thomas was going to pick up her two children in school. She was waiting in front of the class, looking at the learning process in the classroom. She saw her son did not listen to the teachers' explanation. Steven was shredding paper, while Philip was drawing something. Suddenly, there was a classmate of them who had just come from the toilet. Corinne-Morgan Thomas asked to her whether she knew Steven and Philip or not. Corinne became upset because the girl said that both Steven and Philip were very weird boys. 


\section{Utterances:}

Teacher: (4.1) When you add an 'E' on the end of some words, it will change the vowel sound.

(The teacher wrote on the board about what she said).

(4.2) It will change from a short vowel, a short 'A' like in cat to a long 'A' in cake.

(4.3) And that's what these little symbols mean.

(4.4) So a little hat on the 'A' when it's a short 'A' - cat and a straight line over the long ' $A$ '.

\section{Data Analysis:}

In datum 4, teacher as the caretaker produces four kinds of utterances. On 4.1, 4.2, 4.3 and 4.4, she uses representational function. It is because she wants to deliver what she knows to the children who do not understand such knowledge. In this case, the teacher conveys the facts and knowledge about phonology to her students. This function is commonly used in the learning process because the duty of a teacher is telling something that students still do not understand.

In conclusion, datum 4 consists of four utterances. They have the same language function, representational function. In this case, the representational function is not effective because Steven and Philip do not listen to what is described by the teacher. It shows that representational function is not effectively used to communicate with Steven and Philip.

\section{Datum 5}

\section{Context:}

Corinne Morgan-Thomas rented a room at the Rainbow Motel. She and her two autistic children move into a motel for a while. When they were in the room for the first time, Philip and Steven were very scared. Philip covered her ears with her hands, while Steven moved his body forward and backward. Corinne Morgan-Thomas tried to convince the two children that they would be fine.

\section{Utterances:}

Mother: (5.1) Ok, Come on!

(She encouraged his sons' shoulder and led them into the room).

(5.2) Ok, this is going to be our new home for a little while.

(Mother put her bag on the floor while Steven sat on the table and Philip sat on the bed).

(5.3) $O k$, I'm a little scared too.

(She looked at both Philip who covered his ears with his hands and Steven who moved his body forward and backward).

(5.4) We are going to be alright.

(She closed the door). 


\section{Data Analysis:}

In datum 5, mother as the caretaker produces four kinds of utterances. On 5.1, she uses regulatory function. It is because she gives a command to her autistic twin children to follow her instructions. She also uses physical prompt because her children need physically help to response correctly about her command. In this case, she encourages her sons' shoulder slowly. So that, her two children understand what she ordered. In fact, Steven and Philip do what her mother commanded.

On 5.2, mother as the caretaker uses representational function. It is because mother wants to tell something to her autistic twin children. This is the only function that many adults have because they already have knowledge to interpret something which they have seen or heard it. In this case, mother tells both Steven and Philip if they will stay in that room for a while. Mother also uses gestural prompt by look around the room. Both Steven and Philip do not respond but they seem that they understand what his mother says because they look around the room for a moment.

On 5.3 and 5.4, mother as the caretaker uses personal function. It is because she wants to express her own feeling about the room that will be their home for a while. She says that she also feels a little scared to stay there after she saw Steven and Philip whom look very scared. Then, she tries to make her children calm, by saying that they will be fine.

In conclusion, datum 5 consists of four utterances. They have three different language functions such as regulatory function (5.1), representational function (5.2) and personal function (5.3 and 5.4). All three kinds of language functions above are not responded by the autistic children verbally. Yet, on 5.1 which use regulatory function, Steven and Philip look around the room for a moment while their mother uses gestural prompt by look around the room. It means that regulatory function (5.1) is effective because the autistic twin children understand about what their mother says to them then look around the room.

\section{Datum 6}

\section{Context:}

Phillip and Steven were studying in the classroom. The teacher was telling a story about the lion and the mouse. Phillip always imitated what the teacher said. Philip also did not look at his teacher and he just drew something in his notebook.

\section{Utterances}

Teacher: (6.1) The mouse herds the lion's loud roar and went to see what was the matter. (Teacher read a story from a book in front of the class).

(6.2) The lion cried and cried with pain. 
(Phillip mimiced what is said by the teacher. She said, "cried and cried with pain." The teacher looked at Phillip for a while then went back to read a story).

(6.3) and looked at the little mouse and asked the little mouse if he would pull the thorn from his paw.

(Teacher read a story and occasionally looked at her students).

(6.4) The little mouse grabbed hold of that thorn and.

(Phillip returned to say "and cried and cried with pain" and all of his classmate laugh to him).

(6.5) He grabbed hold of the thorn and pulled it out of the lion's paw.

\section{Data Analysis:}

(Teachers continued to read a story and did not concern on Phillip).

In datum 6, teacher as the caretaker produces five utterances. On 6.1, 6.2, 6.3, 6.4, and 6.5 , teacher uses imaginative function. It is important because teacher creates an imaginary system or ideas to the student. In this case, the teacher reads a story about a lion and a mouse. Teacher also uses intonation and rhythm in accordance with the content of the story, so that students are more interested in the story. It proves successful as all students listen to what is said by their teacher except Phillip. He is drawing something in his notebook and occasionally gives a response in a way imitating what the teacher said as on 6.2 and 6.4. On 6.2, Phillip mimics what the teacher said while 6.4, Phillip tries to continue what his teacher wanted to say. Teacher said: " The little mouse grabbed hold of that thorn and ..." and he did not finish his words, but Phillip had said, "And cried and cried with pain." Phillip seems very fond of saying the sentence because it was read with a different intonation by the teacher. It shows that Phillip gives a response to this language function even though he continues to draw something in his notebook and just mimic what teacher said. Phillip also indicates that he likes teacher's intonation while reading phrase "cried and cried with a pain" because Phillip only wants to imitate those phrase. Then he repeats it for several times.

In conclusion, datum 6 consists of five utterances. They have the same language function, imaginative function. In this case, the teacher wants to create an imaginary system or ideas to the student by reading a story about lion and the mouse. Phillip can give a response verbally by imitating what the teacher says as on 6.2 and 6.4. It shows that imaginative function effective because Phillip can respond verbally although he just mimics what the teacher said. 


\section{Datum 7}

\section{Context:}

Mother was visited by a therapist named Wayne Cosgrove. He was sent by the school board to set up Steven and Phillip to be able joining regular classes. He also said that Steven and Phillip would be taught on how to speak, read and write. Then they go into the house to immediately begin the process of teaching. The therapist has said that he would have shown a way that could have been done the mother to teach children with autism. That way called "Baby Steps".

\section{Utterances}

Therapist: (7.1) Chalk ... chalk.

(The therapist picked up a chalk and then drew a line on the blackboard over and over again. He also explained to her that doing repetition many times was the way to teach children with autism. Steven who sat in front of a therapist did not want to mention the word "Chalk" while Phillip who sat in the distance and played with his toys could mimic to say "Chalk").

(7.2) Chalk.

(Steven tried to take the chalk which was brought by the therapist, but the therapist

\section{Data Analysis:}

did not give it and re-draw the lines on the blackboard).

In datum 7, therapist as the caretaker produces two utterances. On 7.1 and 7.2, therapist as the caretaker produces two utterances and uses interactional function. It is because important for the therapist to have a good and close relationship with them (Steven and Philip) in order to get their attention. In this case, interactional function is classified as requiring a response because the therapist wants to Steven imitating what he said. The therapist also uses verbal cues with the aim that Steven can mimics what he says. Unfortunately, Steven still has not respond verbally while Phillip could mimic what therapists say even if he seems does not notice.

In conclusion, datum 7 consists of two utterances. The language function which is used by the caretaker is interactional function. In this case, only Phillip who gives a response by mimicking about what therapist says (7.1). It shows that interactional function here is effective for Phillip in this situation because only Phillip who gives a response.

\section{Datum 8}

\section{Context:}

The therapist began his lesson at Corrine-Morgan Thomas house. He showed a picture of an object and then told Steven to take the object in the box. The box contained variety of objects. 


\section{Utterances:}

Therapist: (8.1) Now, those are blocks... blocks. That's it.

(Therapist showed a picture then Steven picked up a red blocks from the box)

(8.2) Find the ball. Find the ball. Okay.

(Therapist showed a picture then Steven picked up a green ball from the box)

(8.3) You got a ball. Good job.

(8.4) Alright. Blocks, blocks. Can you find a block?

\section{Data Analysis:}

In datum 8, therapist as the caretaker produces four utterances. On 8.1, 8.2 and 8.4, he uses regulatory function. It is because he gives Steven a command in order to get an attention from Steven to follow her instructions. In this case, therapist commands Steven to find an object in the box. He also uses model cues by showing a picture of object which has to search. It makes Steven gets better understanding what object that he should take from the box. Steven gives a response by taking an object which is ordered by the therapist.

On 8.3, therapist as the caretaker uses personal function. It is because he wants to express his own feeling to Steven that he does a good job. In this case, therapist says good job because Steven can find all the objects that he orders.

In conclusion, datum 8 consists of four utterances. They have two different language functions such as regulatory function (8.1, 8.2 and 8.4) and personal function (8.3). All kinds of language functions above are responded by Steven. Steven gives a response in regulatory function such as on utterance 8.1 and 8.4 , Steven can find blocks while on utterance; on utterance 8.2 , Steven can find a ball from the box. It shows that regulatory function is effectively used in this condition.

\section{Datum 9}

\section{Context:}

The next day at Corrine-Morgan Thomas' house, the therapist gave the same lesson to Steven and Phillip. But this time the object was fruits.

\section{Utterances:}

Therapist: (9.1) This is an apple. It's red. It is round, sort of round. It's got a stem. (Therapist showed a red apple to Phillip). (9.2) B-O-W-L bowl, apple in a bowl.

(Therapist showed the bowl picture, and then Phillip put the apple into the bowl). (9.3) Feel this orange. It's all rough. There's the orange. (Phillip took an orange from the therapist's hand, and then he twirled it in his hand). 


\section{Data analysis:}

In datum 9, therapist as the caretaker produces three utterances. On 9.1, 9.2, and 9.3, therapist uses imaginative function. It is because therapist creates an imaginary system or ideas to Phillip about the form of fruits. Therapist also uses model cues in order to make Phillip get better understanding about kind of fruits. On 9.1 and 9.3, therapist shows how the shape and color of the apple and orange fruit. On datum 9.2, a therapist shows a picture of a bowl so Phillip can imagine about the shape of a bowl. In this case, Phillip gives a response by taking the fruit as told by a therapist. Phillip is also directly react when the therapist says "apple in a bowl" by taking an apple and put it into the bowl.

In conclusion, datum 9 consists of three utterances. The language function which is used by the caretaker is imaginative function. In this case, Phillip gives a response to what the therapist says. On datum 9.1 Phillip gives a response by takes an apple, on datum 9.2 Phillip gives a response by takes an apple then put it into bowl, and on datum 9.3 Phillip gives a response by takes an orange from the therapist's hand. It shows that imaginative function is effectively used in this condition.

\section{Datum 10}

\section{Context:}

At night, mother repeated the lesson from therapist. They sat around a round table. There was an orange, an apple, and a glass in that table. Mother tried to teach Phillip, while Steven was playing with blocks in the other side of Phillip.

\section{Utterances:}

Mother: (10.1) Show me the apple!

(Mother showed an apple picture. Phillip then began to select the objects in the table because there were an apple, an orange and a glass. Phillip managed to pick an apple and showed it to his mother).

(10.2) Good, good boy, okay. (Mother smiled as she looked toward Phillip)

(10.3) Alright, show me, show me the glass!

(Mother showed a picture of a glass, and then Phillip took the glass on the table) (10.4) Show me the orange!

(Mother showed a picture of an orange, and then Phillips took an orange from the table).

\section{Data Analysis:}

In datum 10, mother as the caretaker produces four utterances. On 10.1, 10.3, and 10.4 she uses regulatory function. It is because mother gives Phillip a command in order to get an attention from Phillip to follow her instructions. In this case, mother commands Phillip to find an object on the table. She also uses model cues to Phillip by showing a picture of 
object that must be search by Phillip. It makes Phillip gets better understanding what object that he should take from the table. Phillip gives a response by taking an object which is ordering by mother.

On 10.2, mother as the caretaker uses personal function. It is because she wants to express her own feeling to Phillip that he does a something good. In this case, mother says good boy because Phillip can find all the objects that she orders. Phillip doesn't give a response while mother says that.

In conclusion, datum 10 consists of four utterances. They have two different language functions such as regulatory function (10.1, 10.3 and 10.4) and personal function (10.2). Phillip gives a response only in regulatory function. On datum 10.1, Phillip gives a response by taking an apple, on datum 10.3 Phillip gives a response by taking a glass, and on datum 10.4 Phillip gives a response by taking an orange from the table. It shows that regulatory function here is effective for this condition.

\section{CONCLUSION}

Based on the research question and discussion of the data presentation and analysis, the following conclusion can be described dealing with the language function used in Miracle Run film. The language functions used in conversation between caretakers and the autistic children based on time sequence appearances in Miracle Run film are regulatory function, personal function, interactional function, representational function and imaginative function. The language functions are effectively used by caretakers in Miracle run film are regulatory function, imaginative function and interactional function. Kind of respond mostly effective in the film is 'non verbal respond'. The types of language function that not used by caretakers in talking to autistic children in this film are instrumental function and heuristic function.

\section{BIBLIOGRAPHY}

Anderson, Lorin W. 1989. The Effective Teacher: Study Guide and Readings. New York: McGraw-Hill.

Caldwell, Phoebe., and Jane Horwood. 2010. Using Intensive Interaction and Sensory Integration: a Handbook for those who Support People with Severe Autistic Spectrum Disorder. London: Jessica Kingsley Publisher. 
Clark, H, H., and Clark, E, V. 1997. Psychology and Language: An Introduction to Psycholinguistics. USA: Harcourt Brace Jovanovich, Inc.

Dale, P, S. 1972. Language Development: Structure and function. Illinois: The Dryden Press, Inc.

Halliday, M. A. K. 1992. Explorations in the Functions of Language. London: Edward Arnold Ltd.

Holmes, Janet. 1992. An Introduction to Sociolinguistics. England: Longman Group UK Ltd.

Hutcby, Ian. and Wooffitt, Robin. 1998. Conversation Analysis: Principles, Practice and Applications. Cambridge: Polity Press.

Kessler, C. (Ed). 1992. Cooperative Language Learning's. New Jersey: Prentice-Hall, Inc.

Lightbrown, Patsy, M., and Nina, Spada. 1993. How Languages are Learned. Oxford: Oxford University Press.

Littlewood, William. 1984. Foreign and Second Language Learning. Cambridge: Cambridge University Press.

McCarthy, Michael. 1991. Discourse Analysis for Language Teachers. Cambridge: Cambridge University Press.

Roberts, Brian,. and Barbara, Furneaux. 1977. Autistic Children: Teaching, Community and Research Approaches. London: Routledge and Kegan Paul.

Ruswan, Nani. 2005. A Study of Sentence Patterns Produced by an Autistic Child. Unpublished Undergraduate Thesis. Surabaya: Petra Christian University.

Siegal, Byrna. 1996. The world of Autistic Children. New York: Oxford University Press.

Yule, G. 1985. The Study of Language. Cambridge : Cambridge University Press.

Yule, G. 1996. Pragmatics. Oxford: Oxford University Press. 